Bundesgesundheitsbl 2009 · 52:1099-1104 DOI 10.1007/s00103-009-0954-x

Online publiziert: 21. Oktober 2009

(c) Springer-Verlag 2009

\author{
M. Wiese-Posselt · S. Reiter · A. Gilsdorf · G. Krause \\ Department for Infectious Disease Epidemiology, Robert Koch-Institut, Berlin
}

Childhood immunisation schedules in the different member states (MS) of the European Union (EU) show varying diversity in respect to age of administration as well as types and numbers of vaccinations [1]. These schedules are generally developed at the national level by the respective national committees on immunisation (NCI) and are influenced by local requirements. With increasing globalisation of vaccine development, licensing and marketing it might appear a logical consequence that immunisation schedules should therefore become more uniform within the EU.

The European Commission (EC) has started an initiative for a council recommendation on cross-border aspects of childhood immunisation. The objective of this initiative is to establish a scientifically substantiated and flexible immunisation schedule with the widest possible time margins in which a child should be immunised against a set of priority diseases (reference immunisation schedule) [2, 3]. The European Centre for Disease Prevention and Control (ECDC) has recently addressed this issue by generating scientific advice with the objective to realise a reference childhood immunisation schedule regarding diphtheria-tetanus-pertussis (DTP) vaccination [2]. Although the EC has stated that the initiative does not seek to harmonise the different national immunisation schedules, the aim to produce one scientifically substantiated European immunisation schedule in respect to timing and number of doses of, e.g., DTP vaccination in childhood implies that this reference schedule might be the only one scientifically maintainable. However, different national immunisation schedules could be well justified and a unification of immunisation schedules across EU MS may lead to only limited benefits or even to detrimental effects. In the following we aim to address those issues focussing on the public health perspective.

\section{Availability of evidence}

Looking at the large variation between immunisation schedules across the EU, one wonders whether these are in fact all well founded by evidence. For example, currently children and adolescents receive between 4 and 7 doses of diphtheria and tetanus (DT)-containing vaccines until their $18^{\text {th }}$ birthday depending on the different national immunisation recommendations [1]. If national committees on immunisation (NCI) have come up with such extreme differences it may be an indication that those committees have generated their recommendations on the basis of divergent or lacking evidence. The committee's judgement on the public health relevance of a respective vaccination could then have resulted in different recommendations. This may indeed be detrimental in convincing clinicians, vaccinees and their care takers for a recommended immunisation schedule and it may fuel scepticism against immunisation in general. If the diversity in national immunisation recommendations is in fact caused by lack of evidence, then the logical consequence would be to increase every effort to generate the necessary evidence.
There are already various approaches to intensify the evidence-based public health (EB-PH) methodology in the decision making process for immunisation schedules [4]. NCI and national public health institutions are already increasing their efforts towards transparent decision making procedures and comprehensible, evidence-based recommendations. Those efforts at the national level could well be supported and facilitated by multinational (e.g. EU) activities, for example by conducting and analysing systematic literature searches and by facilitating, coordinating or conducting those epidemiological studies needed to answer the relevant open questions. The results could then be taken into consideration by the different NCI together with other local determinants. Such support, for example by the ECDC, would be of immense European added value.

However, in order to make such products useful for the NCI, there must be consensus on how to collect, structure and present the scientific evidence. This includes a standardised approach of systematic literature searches, a common methodology to identify and to grade the quality of evidence and the strength of recommendation. The Grading of Recommendations Assessment, Development and Evaluation (GRADE) Working Group and the Scottish Intercollegiate Guidelines Network (SIGN) have already developed very useful concepts in this field [5, 6]. The ECDC and the Robert Koch Institute have just initiated a process in which the application of GRADE and SIGN for public health recommendations is be- 
ing examined together with experts from national public health institutions. This could eventually lead to a common concept of how evidence for public health recommendations is to be processed and presented. If such an agreement could be reached within the EU, this could set the foundation for the gradual development of uniform immunisation schedules.

\section{Reasons for differences in national immunisation schedules}

Such foundation of evidence will lead to more consistent immunisation schedules, but NIC may well come up with different recommendations even if the same evidence is used. The reason for this is that the country specific situation may differ in many ways that may have an impact on the immunisation strategy. The most important topics to consider here are country specific differences in (a) values and goals, (b) epidemiological situation, (c) healthcare delivery system, (d) logistics of vaccine delivery, and (e) economic situation:

\section{Values and goals}

Immunisation schedules are a specific form of public health interventions and are influenced by respective values and health goals of a society. The acceptability of a recommended vaccine among those who prescribe and administer it, as well as among the recipients and their care takers is of immense importance for the success of an immunisation strategy. Therefore, feasibility of an immunisation programme is closely linked to acceptability which in turn is largely influenced by cultural values of a society. The goal of an immunisation programme may be to reduce the disease burden in risk groups or in the whole population. It may include other positive epidemiological effects such as herd immunity or the eradication of a pathogen or it can be limited to individual protection. Some EU MS already define their aim quantitatively, e.g. a 90\% reduction of a vaccine preventable disease (VPD) within a certain time frame. This is of course likely to affect the immunisation strategy and thus the respective immunisation schedule.
The WHO goal of measles eradication by 2010 in the European region is such an example [7]. The target is to eradicate measles or reduce morbidity and mortality due to measles. Children should, therefore, receive two doses of measles-containing vaccine but it is not predetermined which schedule should be used (two doses within the second year of life or first dose in the second year of life and the second dose before school entry or even later) [1].

This means that before one uniform immunisation schedule can be established, agreement is needed about the public health goals to be achieved.

\section{Different epidemiological situations}

Although, one might expect very similar living conditions across the EU, differences in the local epidemiology may well justify different immunisation schedules. The annual epidemiological report on communicable diseases in Europe produced by the ECDC shows important differences in the epidemiology of VPDs [8]. For diphtheria for example, high numbers of cases were reported from Latvia (32 cases in 2006), while in other MS no case of diphtheria has occurred in recent years [8]. Although all European countries have integrated pertussis vaccination into their routine immunisation schedule, pertussis incidences vary between < 0.1 (e.g. Romania) and 142.0/100,0oo population (Norway) in 2006 [8].

Hepatitis B is another example: the reported surveillance data show a hepatitis B incidence between 0.29 (France) and 10.0/100,000 population (Bulgaria) in 2006 [8]. The disease burden of hepatitis $\mathrm{B}$ is not only defined by the incidence but other possible influencing factors have to be taken into account, such as age-specific incidences, prevalence of HBsAg carriage, the detection of persons at high risk for infection and the frequency of hepatitis B in these persons (i.v. drug users), success of infection control measures already implemented etc. [9]. As a result of such considerations universal childhood vaccination against hepatitis B can be very effective in some MS; however in other MS with a low incidence a selective programme may be more appropriate.

\section{Different health care systems}

The burden of disease is not only defined by the incidence but also by factors which largely depend on an individual country's health care system. The way curative care is organised may have large implications on the societal cost of one illness and even on the case fatality rate and therefore, on local immunisation recommendations.

Immunisation also has to be viewed in relation to the availability of other preventive options such as hygienic measures or chemoprophylaxis. Depending on the availability and (cost) effectiveness of such complementary measures in the different MS the national immunisation strategies might also differ.

\section{Different logistics of vaccine delivery}

In order to accomplish high vaccination coverage, the timing of a certain vaccination should be considered in a timeframe when children are easy to reach. Immunisation can be promoted in an optimal way if vaccinations are given at the same time that routine child health screenings are scheduled. Depending on the system of childcare and age of school entry, children are exposed and reachable for immunisation at different ages in the different MS. That also affects the immunisation schedules and leads to the diversity between MS.

\section{Different economic situations}

All above mentioned factors will result in different costs and thus have implications on the cost effectiveness or cost benefit analysis in the different MS. Budgets for health services vary greatly between MS and the budgets for immunisation in a respective country may simply not allow a change in the immunisation schedule, which will result in increased expenditures, even if it is cost effective on the overall societal level. Therefore, a vaccine might not be recommended for routine immunisation although there is high 
quality evidence on the effectiveness and safety of this vaccine.

\section{Justifications for uniform immunisation schedules}

As described above, we could detect numerous reasons for the diversity of national immunisation schedules in $\mathrm{Eu}$ rope. However, the European Commission (EC) is preparing a council recommendation on diphtheria-tetanus-pertussis (DTP) vaccination in childhood and the ECDC has created the ECDC's Scientific Panel on Childhood Immunisation Schedule (SPACIS) which should give advice about how to establish a reference immunisation schedule regarding DTP vaccination in childhood [10]. This panel has already developed policy options on how to immunise children less than two years of age against DTP and regarding minimal booster doses which should be given until the $18^{\text {th }}$ birthday. After feedback from the MS the draft document of the SPACIS on DTP vaccination is now under revision [10]. In the document it is reported that the SPACIS expert panel focused on three questions:

- What is the best age (or age range) to start the basic immunisation scheme for a combined diphtheria-tetanuspertussis (DTP) vaccine?

- What is the minimum number of doses and what are the best immunisation intervals to provide sufficient protection against DTP in infants younger than two years of age?

- What is the minimum number of booster doses that should be administered between two and 18 years of age, and what are the best intervals between doses?

More of such activities in respect to other VPDs are planned by the EC [2]. The arguments listed to justify uniform immunisation schedules are that these schedules would (a) be necessary to assure mobility of EU residents within the EU, (b) allow MS to jointly negotiate lower vaccines prices with the manufacturers, (c) be limited to recommending minimal effective schedules, (d) reduce the need for clinical trials, (e) facilitate collection of EUwide data on evaluation of surveillance

Bundesgesundheitsbl 2009·52:1099-1104 DOI 10.1007/s00103-009-0954-x

(c) Springer-Verlag 2009

\section{Wiese-Posselt · S. Reiter · A. Gilsdorf · G. Krause \\ Needs and obstacles of uniform immunisation schedules in the European Union}

Abstract

Immunisation schedules are developed by national committees on immunisation and may differ considerably between the European Union (EU) member states (MS). The European Commission has launched an initiative for a council recommendation with the aim to establish a scientifically substantiated reference childhood immunisation schedule for the EU. In our view this initiative implies the establishment of one European childhood immunisation schedule, which could lead to the perception that this schedule is the only one scientifically justified. The expectations that one uniform immunisation schedule will facilitate mobility of EU residents, improve data collection and increase vaccination coverage are either quantitatively or qualitatively not relevant or even ethically problematic. Arguments that uniform schedules would lead to lower vaccine prices and reduce the need for clinical trials appear to be more relevant but could be addressed more effectively by other measures. On the other hand the following factors may differ substantially between MS and thus support different immunisation schedules, such as (a) values and goals, (b) epidemiological situation, (c) health care delivery system, (d) logistics of vaccine delivery and (e) economic situation. We argue that uniform schedules should not be perceived as a goal in itself but rather as a possibly desired by-product following increasing agreement on goals and values between MS and improved evidence base to be used by national committees on immunisation.

Keywords Immunisation · Immunisation schedule · Vaccines · European Union

\section{Notwendigkeiten und Hürden einheitlicher Impfempfehlungen in der Europäischen Union}

\section{Zusammenfassung}

Impfempfehlungen werden von nationalen Impfkommissionen erarbeitet und können sich zwischen den Mitgliedsstaaten (MS) der Europäischen Union (EU) erheblich unterscheiden. Die Europäische Kommission startete eine Initiative für eine Empfehlung des Rates mit dem Ziel, einen europäischen, wissenschaftlich fundierten Referenz-Impfkalender für Kinder zu entwickeln. Unserer Meinung nach impliziert diese Initiative die Etablierung eines einzigen europäischen Impfkalenders, der als der einzig wissenschaftlich zu rechtfertigende bewertet werden könnte. Die Erwartungen, dass ein einheitlicher Impfkalender die Freizügigkeit von EU-Bewohnern erleichtern, die Datenerfassung verbessern und die Impfquote erhöhen könnte, erscheint quantitativ und qualitativ nicht relevant oder sogar ethisch bedenklich. Impfstoffpreise und der Bedarf für klinische Studien könnten durch einheitliche Impfkalender gesenkt wer- den, aber dies könnte durch alternative Maßnahmen sogar effektiver gelingen. Auf der anderen Seite unterscheiden sich folgende Faktoren zwischen den MS erheblich und begründen unterschiedliche Impfkalender, wie a) Werte und Zielsetzungen, b) epidemiologische Lage, c) Gesundheitsversorgungssysteme, d) Impflogistik und e) wirtschaftliche Situation. Die Vereinheitlichung von Impfkalendern sollte nicht als primäres Ziel gesehen werden, sondern allenfalls als Nebeneffekt infolge zunehmender Einigung über Ziele und Werte sowie einer verbesserten Evidenzgrundlage, die von nationalen Impfkommissionen verwendet werden könnte.

Schlüsselwörter

Schutzimpfungen · Impfkalender · Impfempfehlungen · Europäische Union 
programmes, and (f) increase the vaccination coverage $[2,3,10]$. In the following we would like to address those arguments:

\section{Mobility of EU residents}

The efforts to establish uniform immunisation schedules are often being justified by the potential difficulties of EU residents moving with their children from one MS to another one with a different childhood immunisation schedule. It is being argued that difficulties of completing an immunisation schedule in another country may cause a decrease of the immunisation compliance, an increase of the workload of healthcare workers and ultimately stand in conflict with the right of free movement of EU residents [11].

Although migrating families might be confronted with the decision to either follow the schedule of the old or the new country of residence, there is little reason to believe that this will affect vaccine compliance. And even if this problem does in fact exist, it would only affect a very small number of vaccinees: Taking the example of Germany - the member state with the largest population ( 82 million) in the EU - national statistics from 2006 indicate that 64,735 German residents moved to another MS; of them, 304 were children younger than 1 year of age and 869 were 1-2 years old [12]. In other words, based on a birth cohort of around 700,00o newborns per year in Germany roughly between $0.04 \%$ and $0.12 \%$ per birth cohort, might have been affected by migration in 2006. The number of children actually confronted with substantially different schedules is certainly much smaller, because in many cases national immunisation schedules are identical or similar depending on the exact age at which a child is moving. And even this small number of children will not necessarily encounter difficulties: Since vaccines are licensed commonly for the EU market by the European Medicines Agency (EMEA) every licensed vaccine product can be purchased and used in every MS [13]. If a licensed vaccine is not easily available in one MS it can be imported from another MS. Thus, a started immunisation series in one MS can always be completed. From
2001 to 2008, the Robert Koch Institute has received over 10,500 e-mail requests through its immunisation hotline for physicians and health care workers; only one of these requests dealt with the question how an immunisation series which had been started in another MS should be continued in Germany. In any case - with or without migration - it is the responsibility of the physician to decide which vaccine to administer, taking into account primarily national recommendations but also health status of the vaccinee and individual and geographical risk assessment. Therefore, the issue of migration is negligible in size and quality.

\section{Lower vaccine prices}

One argument favouring uniform immunisation schedules is that more countries could initiate joint negotiations with the manufacturers since the required products would be identical. Although this argument is initially appealing, it does not necessarily require uniform immunisations schedules: First of all several countries already have had identical immunisation schedules for many years, but to our knowledge none of them have yet come together to organise joint negotiations for vaccine prices. Several EU MS do already negotiate successfully with vaccine manufacturers on a national basis. But in some EU MS the structure or organisation of health care systems does not allow the option of negotiations with vaccine manufactures. In Germany, for example, the vaccine market is not regulated by public authorities and the government does not have the possibility to negotiate with manufactures about the vaccine prices or products tailored to suit the German situation [14]. Only the German Statutory Health Insurances (SHI) are able to negotiate with the vaccine manufacturers on a discount of vaccine prices [14]. Around 200 SHI exist in Germany and no agreement with respect to vaccine prices has been reached so far between a SHI and a manufacturer [15]. This is a good indication that uniform immunisation schedules across the EU would not necessarily result in the ability of MS to jointly negotiate lower vaccine prices.
Second, the principal basis for negotiating lower prices for larger amounts of any given product is twofold. On the one hand a manufacturer can limit the variation of products and thus reduce production cost; on the other hand a manufacturer can better estimate the market demand and thus optimize production accordingly. For this however, it is not relevant when the buyer will actually use the product (i.e. at what age and how often a vaccine will be administered) but rather when and in what amount the product will be purchased. Admittedly, certain immunisation schedules will eventually result in the need or possibility for vaccine combinations, which could indeed be seen as a common product specification. Nevertheless the largest potential of negotiating lower prices lies within the uniformity of product licensure. This potential which is already reached by the EMEA has yet to be used, and experiences to be gained with it, before going to the next step which would be to initiate the establishment of uniform immunisation schedules.

One might also argue that the main goal of the EU treaty is to create a common market, but its application to vaccines would simply mean that products are accessible and marketable through the EU [16]; this is already guaranteed by the uniform EMEA licensing procedure. But the EU treaty does not cover uniform recommendations indicating at what age a customer should use a certain product (i.e. vaccine).

\section{Minimum effective schedules}

In recent efforts of the ECDC to generate guidance on diphtheria-tetanus-pertussis (DTP) vaccination it has been argued that the guidance would only go as far as giving options for "minimal" effective doses [10]. This implies that it leaves all liberty to the national committees on immunisations (NCI) and to the individual prescribers to go beyond such minimal schedules. However, this is not necessarily the logical conclusion: In pharmacology in general the minimal effective dose is at the same time the only justified one. Because if evidence suggests that more doses would not be more effective, any dose in addition to the effective minimum dose will 
increase the risk for adverse effects. This is even particularly relevant in vaccinology as it implies exposing healthy persons to a medical intervention, even if it is generally agreed that serious adverse effects of modern vaccines are very rare. Therefore "minimal effective schedules", a term that was selected to avoid the term "recommendations", are in fact recommendations and a NCI might face controversial public arguments if it decides to issue a recommendation different from the $\mathrm{EU}$ minimal effective schedules, even if it is based on national peculiarities.

\section{Fewer clinical trials}

Different immunisation schedules will result in different interactions between different vaccines or vaccine components. This in fact results in the need for clinical trials and will ultimately lead to more children or adults being exposed to such trials. While this is true, the same logic would apply to the vaccine market diversity in general, which would ultimately lead to the conclusion that in Europe only one manufacturer should be in charge to develop and produce a specific vaccine. Certainly, the latter approach would reduce the overall need for clinical trials to a much larger extent than through establishment of uniform immunisation schedules. However for other reasons it seems not to be worthwhile to strive for vaccine production monopoly in Europe.

\section{Ease of data collection}

Another argument stated by those favouring uniform immunisation schedules is the idea that if they were more comparable it would also be easier to generate comparable figures on vaccination coverage, vaccine effectiveness and vaccine safety. This would mean that all healthy individuals in Europe are supposed to submit themselves to one uniform medical intervention just for the sake of making it easier for international public health institutions and pharmaceutical companies to collect the data needed for such interventions. Such argumentation would be largely unethical. On the contrary, one might argue that the diversity of immunisation schedules actually allows large-size obser- vational comparisons of effectiveness and safety of certain schedules. In addition, a uniform immunisation schedule within the EU will not necessarily be linked with uniform surveillance instruments in the different MS.

EU funded projects and projects now hosted at ECDC are already addressing those issues, such as the Vaccine European New Integrated Collaboration Effort (VENICE), which aims to encourage collection and dissemination of knowledge and best practice relating to vaccination [17]. One of the specific objectives of VENICE is to define common indicators for monitoring the immunisation programmes across the MS. If the aim of an immunisation programme is defined consistently, then EU common monitoring is possible while different immunisation schedules are used.

Another European-wide project is EUVAC.NET which was created for the purposes of epidemiological surveillance and control of VPDs in the European community [1]. In this network epidemiological data should be collected in order to support MS in the decision making process of new vaccines and in evaluation of existing immunisation strategies.

\section{Increased vaccination coverage}

In the documents discussing the minimal effective schedule it is stated that these schedules will increase the vaccination coverage $[2,10]$. There seems to be no real evidence for this statement. As already mentioned issues regarding vaccine delivery and timing of vaccinations seem to influence the vaccination coverage. Again we would like to refer to an example from Germany where the measles-mumps-rubella (MMR) vaccination is given in two doses within the second year of life. This schedule is divergent to MMR vaccination schedules in many other MS, where the second dose MMR is given for example by school entry [1]. Although there are no uniform MMR vaccination schedules within Europe, vaccination coverage of the second dose MMR vaccine increased considerable in Germany from $33 \%$ coverage in the 5 to 6-year-old children in 2002 to $88 \%$ coverage in 2007 , because in 2001 the schedule changed and the second dose
MMR should be administered before the $2^{\text {nd }}$ birthday $[18,19]$. Other local aspects are influencing the vaccination uptake as attitudes of the population towards immunisation in general and its awareness in respect to the safety of a certain vaccine or the promoting of immunisation by the physicians, midwives or other medical care givers and by the media, respectively. Finally, the aspect of reimbursement of vaccinations - which is organised differently in the MS - might influence vaccination coverage, as well.

Under careful consideration of the arguments for the proposal to facilitate one uniform childhood immunisation schedule or uniform schedules in the EU, we feel that they are either quantitatively and qualitatively not relevant or substantial (mobility of residents, minimal effective schedule, ease of data collection, increasing vaccination coverage) or if they are relevant (lower vaccine prices, fewer clinical trials) various other measures could more effectively address them.

\section{Conclusion}

EU-wide establishment of uniform childhood immunisation schedules could have some benefits, but it is not a goal by itself and should rather be seen as logical and desirable by-product of two developments: firstly, increased agreement on common vaccination goals and general values and secondly, improved evidence based decision making approaches for recommendations on immunisation. The $\mathrm{EU}$ and its respective agencies such as the EMEA and the ECDC should focus on facilitating those two developments. This could be accomplished by increasing support for vaccine-related epidemiological research, by continuing the development of a commonly agreed system for generating and grading the scientific evidence, by conducting or coordinating epidemiological research in order to generate the missing evidence, by improving comparability of surveillance data and by moderating the agreement on immunisation goals between the MS. We appreciate that these activities are already taking place and we hope they will be strengthened and also increasingly involve $\mathrm{NCls}$ and other relevant bodies 
in the EU MS. The cooperation between the Advisory Committee on Immunisation Practices (ACIP) in the United States and its "liaison organisations" could be a good example for this [4].

If the EU and its MS have very effective tools at hand to improve and lay out the evidence, it would then be up to the $\mathrm{NCls}$ to generate recommendations based on this evidence. National immunisation schedules will still differ to some extent because of different values in different societies and because of the various other reasons discussed above, but those differences will then be well justified. "Harmonisation" of immunisation schedules resulting from such a process may take somewhat longer than politically motivated council recommendations or selected options of minimal effective schedules. However we believe the evidence-based, multifaceted approach proposed above is likely to be more sustainable and thus more effective in preventing disease in the EU.

\section{Korrespondenzadresse}

\section{Wiese-Posselt}

Department for Infectious Disease Epidemiology, Robert Koch-Institut

DGZ-Ring 1, 13086 Berlin

Wiese-PosseltM@rki.de

\section{Literature}

1. EUVAC.NET European surveillance community network for vaccine-preventable infectious diseases (2009); vaccination schedules by country. http:// www.euvac.net/graphics/euvac/vaccination/vaccination.html

2. European Commission (2009) Commission legislative and work programme 2009. Priority initiatives, no. 32: Council recommendation on cross border aspects of childhood immunisation. pp 102-105. Available at June 16, 2009: http://ec.europa.eu/atwork/programmes/docs/clwp2009_roadmap_priority_initiatives_en.pdf

3. European Commission (2007) Workshop Children's Health 20-21 November 2007. Antoon Gijsens: Childhood immunisation in the EU - mapping the landscape for best practices. Available at June 16, 2009: http://ec.europa.eu/health/ph_information/implement/wp/lifestyle/docs/ev_20071120_ co01_en.pdf

4. Smith JC, Snider DE, Pickering LK (2009) Immunisation policy development in the United States: the role of the Advisory Committee on Immunisation Practices. Ann Intern Med 150:45-49

5. Grading of Recommendations Assessment, Development and Evaluation (GRADE) Working Group (2009) http://www.gradeworkinggroup.org/

6. Scottish Intercollegiate Guidelines Network (SIGN) (2009) http://www.sign.ac.uk/
7. World Health Organisation (WHO) Geneva (2009) WHO/UNICEF joint statement - global plan for reducing measles mortality 2006-2010. http:// whqlibdoc.who.int/hq/2005/QHO_IVB_05_11_ eng.pdf

8. ECDC, Stockholm (2008) Epidemiology of communicable diseases in Europe, pp 258-262. http:// ecdc.europa.eu/en/files/pdf/Publication/081215 AER_long_2008.pdf

9. Nardone A, Anastassopoulou CG, Theeten $\mathrm{H}$ et al (2009) A comparision of hepatitis B seroepidemiology in ten European countries. Epidemiol Infect 137:1-9

10. Scientific Panel on Childhood Immunisation Schedule (SPACIS) (2009) ECDC Guidance, SPACIS: Diphtheria-tetanus-pertussis (DTP) vaccination, Stockholm October 2008. Document under publication, SPACIS, ECDC, Stockholm

11. European Commission, Brussels (2009) Employment, social affairs and equal opportunities $>$ mobility. http://ec.europa.eu

12. Statistisches Bundesamt Germany (2009) Requested data on movement of German citizens to EU member states in 2006. http://www.destatis.de

13. European Medicines Agency (EMEA), London (2009) Structure. http://www.emea.europa.eu/ mission.htm

14. Sozialgesetzbuch (SGB) Fünftes Buch (V) - Gesetzliche Krankenversicherung (1998) §130a Rabatte der pharmazeutischen Unternehmen. http:// bundesrecht.juris.de/sgb_5/

15. GKV-Spitzenverband Bund (2009) Anzahl gesetzlicher Krankenkassen. https://www.gkv-spitzenverband.de/Alle_gesetzlichen_Krankenkassen. gkvnet

16. The Treaty of the European Union, consolidated version (1992) http://eurlex.europa.eu/en/treaties/ dat $/ 12002 \mathrm{E} / \mathrm{htm} /$ C_2002325EN.003301.html

17. European Network on Immunisation Policies (2009) The VENICE Project (2009). http://ecdc.europa.eu/en/Health_Topics/vi/VI_networks.aspx

18. Robert Koch-Institut, Berlin (2001) Epid Bull 28/2001; pp 204. http://www.rki.de/cln_091/ nn_195846/DE/Content/Infekt/EpidBull/Archiv/2001/28_01.html

19. Robert Koch-Institut, Berlin (2009) Epid Bull 16/2009; pp 143-145. http://www.rki.de >Infektionsschutz > Epidemiologisches Bulletin >2009> Epidemiologisches Bulletin 16/2009 